\title{
O USO DO LAPTOP EDUCACIONAL E AULAS DE MATEMÁTICA: POSSIBILIDADES DE INTEGRAÇÃO ÀS PRÁTICAS PEDAGÓGICAS NO ENSINO DE ÁLGEBRA
}

\author{
Fernanda Elisbão Silva de Souza ${ }^{1}$ \\ Suely Scherer $^{2}$
}

\begin{abstract}
Resumo
Este artigo é um recorte de uma pesquisa que teve por objetivo analisar possibilidades de integração do laptop educacional às práticas pedagógicas de professores de matemática no ensino da álgebra do $8^{\circ}$ ano. A pesquisa foi baseada nos estudos das abordagens do uso de computadores na educação e integração de tecnologias ao currículo escolar. A metodologia adotada foi da observação participante, sendo a observação realizada em uma escola pública, de dois professores, durante planejamentos de aulas realizados em parceria com a pesquisadora, e desenvolvimento de aulas com o uso do laptop educacional. Observou-se que os professores apresentaram dificuldades no processo de integração do laptop em suas práticas pedagógicas, mas há possibilidades desta tecnologia ser integrada ao ensino de álgebra do $8^{\circ}$ ano em aulas de matemática, em especial com o uso de applets.
\end{abstract}

Palavras-chave: Práticas Pedagógicas. Abordagens com uso de computadores. Projeto UCA. Álgebra.

\section{USE OF EDUCATIONAL LAPTOP AND MATH CLASSES: INTEGRATION POSSIBILITIES FOR PEDAGOGICAL PRACTICES IN ALGEBRA TEACHING}

\begin{abstract}
This article is part of a research that aimed to examine possibilities of integration of educational laptop to the pedagogical practices of teachers in the teaching of algebra in 8th grade. The research was based on the studies of approaches to using computers in education and integrate technology into the school curriculum. The methodology was participant observation, with an observation made in a public school, two teachers for lesson plans in partnership with the researcher, and developing lessons using the educational laptop. It was observed that teachers had difficulties in the integration of the laptop in their teaching process, but there are possibilities of this technology to be integrated into the teaching of algebra in 8th grade math classes, especially with the use of applets.
\end{abstract}

Keywords: Pedagogical Practices. Approaches to using computers. UCA project. Algebra.

\section{Introdução}

As dificuldades na aprendizagem de álgebra são discutidas por alguns pesquisadores como Gil (2008) e Viola dos Santos (2007), que identificaram que alunos apresentam dificuldades em álgebra, na interpretação de problemas algébricos que exigem uma tradução da linguagem natural para a linguagem simbólica. Esses autores consideraram que as dificuldades são decorrentes de obstáculos como a relação entre a álgebra e a aritmética, e a interpretação de enunciados de problemas envolvendo a álgebra.

Nos Parâmetros Curriculares Nacionais (PCN), identificamos a importância do ensino da álgebra. De acordo com esse documento (BRASIL, 1998, p. 115): “O estudo da Álgebra constitui

\footnotetext{
${ }^{1}$ Mestrado em Educação Matemática. Universidade Federal de Mato Grosso do Sul, UFMS, Brasil. E-mail: fernanda.elisbao@gmail.com

${ }^{2}$ Mestrado em Modelagem Matemática. Universidade Regional do Noroeste do Estado do Rio Grande do Sul, UNIJUI, Brasil. Doutorado em Educação (Currículo). Pontifícia Universidade Católica de São Paulo, PUC/SP, Brasil. Vinculo Institucional: Membro de comitê assessor. Professora da Universidade Federal de Mato Grosso do Sul - (UFMS). Professora do Programa de Pós-Graduação em Educação Matemática - (PPGEduMat). E-mail: susche@ gmail.com
} 
um espaço bastante significativo para que o aluno desenvolva e exercite sua capacidade de abstração e generalização, além de lhe possibilitar a aquisição de uma poderosa ferramenta para resolver problemas.".

Ao considerar a importância de investigar o ensino e a aprendizagem da álgebra, na pesquisa que neste artigo apresentamos um recorte investigou-se possibilidades de integração dos laptops educacionais em práticas pedagógicas no ensino da álgebra.

Os laptops educacionais são oriundos do Programa Um Computador por Aluno (PROUCA), que tem como objetivo o uso de tecnologias para promover a inclusão digital. $\mathrm{O}$ programa foi estruturado pelo MEC, de modo a se integrar aos planos e projetos educacionais de tecnologia educacional. A primeira fase Pré-piloto do projeto Um Computador por Aluno (UCA) aconteceu durante o ano de 2007, em que foram realizados os primeiros experimentos em cinco escolas brasileiras, com o objetivo de avaliar o uso dos computadores portáteis nas salas de aulas. A segunda fase do projeto denominada Piloto teve início em 2010, em que 300 escolas públicas das redes de ensino estaduais e municipais do Brasil foram contempladas segundo alguns critérios. Esta pesquisa surgiu nesse contexto da fase Piloto, em uma das escolas públicas de Terenos-MS, em 2012.

No Projeto UCA, cada estudante da educação básica, das escolas contempladas, recebe um laptop. Assim, muda o cenário da escola: os computadores estão nas mãos dos alunos, em diferentes espaços da escola. Como o projeto tem também o objetivo de promover mudanças na prática pedagógica a partir da inserção de laptops educacionais nas salas de aulas, como pesquisadoras ficamos instigadas a analisar as possibilidades de integração dessa tecnologia ao currículo de matemática, em especial, no campo da álgebra. Para tal analisamos práticas pedagógicas de professores de matemática ao utilizarem os laptops educacionais. A prática pedagógica nessa pesquisa será compreendida como a prática educativa proposta por Zabala (1998, p.23), uma prática que pode ser interpretada:

[...] não apenas a partir do que não se faz com relação a um modelo teórico, mas também como o resultado da adaptação às possibilidades reais do meio em que se realiza. A prática na aula, marcada por estes condicionantes, não é o resultado de uma decisão firme sobre as finalidades do ensino e segundo uma concepção determinada dos processos de ensino/aprendizagem, mas corresponde àquilo que pode se fazer levando em conta a globalidade do contexto educacional em que se desenvolve a prática educativa.

Conforme Zabala (1998), a prática educativa engloba diversas variáveis metodológicas tais como a função social de ensino, os objetivos dos conteúdos trabalhados, concepção de aprendizagem e critérios de ensino. 
É importante destacar que, não basta inserir as tecnologias digitais no ambiente da sala de aula, é necessário integrá-las ao currículo escolar, ao processo de ensino e de aprendizagem.

Este artigo é um recorte de uma pesquisa que teve como objetivo analisar as práticas pedagógicas de professores de matemática ao ensinarem álgebra no $8^{\circ}$ ano do Ensino Fundamental. Para tal serão apresentadas e analisadas práticas dos dois professores participantes da pesquisa com o uso do laptop educacional.

A pesquisa foi desenvolvida em uma escola pública do município de Terenos - MS, da rede estadual de ensino, contemplada com o projeto UCA. A escola foi contemplada pelo projeto UCA em 2010, e foi oferecida uma formação ${ }^{3}$ básica para os professores e gestores sobre o uso dessa tecnologia. E ainda em 2010, alguns professores dessa escola iniciaram o uso do laptop educacional em suas aulas, conforme informado pela supervisora da escola.

Após um convite feito aos professores no Grupo de Estudos do Laptop e Educação Matemática (GELEM) ${ }^{4}$, os dois participantes da pesquisa, voluntariamente aceitaram o desafio de participar desta pesquisa. No segundo semestre de 2012 tivemos a participação da professora que chamaremos de Joana (nome fictício), e quando o professor Carlos (nome fictício) foi contratado, em 2013, para trabalhar na mesma escola em que atuava Joana, também se voluntariou a participar da pesquisa. O período de realização da observação participante na escola foi de agosto de 2012 a maio de 2013.

A professora Joana é professora concursada pela rede estadual de educação, ministra vinte aulas de matemática semanais nos períodos matutino e vespertino, para as turmas dos $6^{\circ}, 7^{\circ}, 8^{\circ}$ e $9^{\circ}$ anos do Ensino Fundamental da escola pesquisada.

O outro participante da pesquisa, professor Carlos, é professor contratado e ministrava em 2013 vinte aulas de matemática semanais para os $8^{\circ} \mathrm{e} 9^{\circ}$ anos do Ensino Fundamental na escola em que foi desenvolvida a pesquisa. E também lecionava para os $2^{\circ}$ e $3^{\circ}$ anos do Ensino Médio e para a Educação de Jovens e Adultos - EJA, nos períodos matutino, vespertino e noturno em outra escola.

Os professores foram acompanhados em seus horários de planejamento, quando em conjunto com uma pesquisadora (uma das autoras deste artigo) definiam ações a serem desenvolvidas em aula com o uso de laptop. As aulas eram desenvolvidas pelo professor e observadas pela pesquisadora, além de avaliadas em conjunto em momento posterior a aula. A análise dos dados foi realizada a partir do referencial teórico adotado, por aulas planejadas e observadas no $8^{\circ}$ ano, abordando conteúdo de álgebra, e com o uso de laptop.

\footnotetext{
${ }^{3} \mathrm{O}$ processo de formação foi proposto pelo MEC e aconteceu em três níveis ou ações e envolveu, além das escolas participantes, as universidades (IES), Secretarias de Educação (SE) e os Núcleos de Tecnologia Educacional. (NTE). A formação teve caráter semi-presencial e foi dividida em 04 módulos, abrangendo as dimensões teórica, tecnológica e pedagógica. Disponível em português no site: 〈http://www.uca.gov.br/institucional/projetoPiloto.jsp〉.

${ }^{4}$ Grupo de estudos vinculado a projeto financiado pelo CNPq, coordenado por uma das autoras deste artigo.
} 


\section{Abordagens do uso de computadores na educação e sua integração ao currículo escolar}

Um dos referenciais teóricos usado na pesquisa foram os estudos de Papert (2008) sobre as abordagens no uso de computadores na educação: a instrucionista e a construcionista.

$\mathrm{Na}$ primeira abordagem encontramos práticas pedagógicas em que o professor passa instruções para os alunos de como resolver uma tarefa usando o computador, deixando-os em um papel passivo. O aluno é instruído pelo professor nessa abordagem, e o computador é utilizado como uma máquina de ensinar. Nessa abordagem, de acordo com Valente (2005), alguém implementa uma série de informações no computador, e essas são dadas aos alunos por meio de exercício-e-prática, jogos ou tutorial.

Essa abordagem pouco favorece a aprendizagem dos alunos, uma vez que nela, basta que os alunos aprendam as instruções e saibam reproduzir, tornando-os dependentes desse processo. $\mathrm{O}$ computador é utilizado como o responsável pela transmissão de informação. Na abordagem construcionista, o aluno é o responsável pelo processo de aprendizagem, construindo conhecimentos de seu interesse. Concordamos, assim quando Almeida (2000, p. 19) afirma:

Nessa abordagem o computador não é o detentor do conhecimento, mas uma ferramenta tutorada pelo aluno, que lhe permite a busca de informações em redes de comunicação a distância, navegar entre nós e ligações, de forma não-linear, segundo seu estilo cognitivo e seu interesse momentâneo.

Almeida (2000, p. 21) enfatiza ainda que, "o uso do computador segundo essa abordagem torna evidente o processo de aprender de cada indivíduo, o que possibilita refletir sobre o mesmo a fim de compreendê-lo e depurá-lo".

$\mathrm{Na}$ abordagem construcionista, Papert (2008) defende que o aprendiz constrói algo por meio do fazer, ou seja, do "colocar a mão na massa". Para este autor, os alunos, com o uso do computador, podem construir conhecimentos, tendo papel ativo no processo de aprendizagem, e, consequentemente, podem refletir sobre suas conjecturas. O professor tem o papel de mediador do processo de aprendizagem do aluno, elaborando problemas que sejam desafiadores, formulando boas questões, e mobilizando os alunos para a exploração, a reflexão, a depuração de ideias e favorecendo a compreensão de conceitos.

Nesse intuito discutimos a importância dos computadores serem integrados ao currículo, de maneira que o uso dessa tecnologia favoreça o processo de aprendizagem dos alunos, e que se diferencie de uma aula com lápis e papel.

De acordo com Bittar (2010, p. 5):

Fazemos uma distinção entre integração para distinguir de inserção. Essa última significa o que tem sido feito na maioria das escolas: coloca-se o computador nas escolas, os professores usam, mas sem que isso provoque uma aprendizagem 
diferente do que se fazia antes e, mais do que isso, o computador fica sendo um instrumento estranho (alheio) à prática pedagógica, sendo usado em situações incomuns, extraclasses, que não serão avaliadas. [...] integrar um software à prática pedagógica significa que o mesmo "poderá deverá" (sic) ser usado em diversos momentos do processo de ensino, sempre que for necessário e de forma a contribuir com o processo de aprendizagem do aluno.

Desse modo, observam-se algumas diferenças entre inserir e integrar o computador na prática pedagógica do professor. No processo de integração do laptop é preciso realizar reflexões sobre o modo que se ensina e articulá-las com mudanças na ação pedagógica e um repensar do currículo da escola.

Para que a integração do laptop educacional aconteça de forma a provocar mudanças na escola, acreditamos que é preciso que o professor atue em uma abordagem construcionista. De acordo com Almeida (2005), é necessário que o professor conheça as características, potencialidades e limitações das tecnologias digitais, de modo a desafiar, questionar e instigar o aluno a construir conhecimento, favorecendo a sua aprendizagem. Assim, o professor precisa planejar atividades conforme os objetivos de aprendizagem das aulas.

\section{O ensino de álgebra no currículo escolar}

No ensino de álgebra, no Guia dos livros didáticos, desenvolvido a partir do Plano Nacional do Livro Didático (PNLD) de 2011 afirma-se que esse ensino deve estar pautado na:

[...] percepção de regularidades, que pode levar à criação de modelos simbólicos para diversas situações, e a capacidade de traduzir simbolicamente problemas encontrados no dia a dia, ou provenientes de outras áreas do conhecimento. [...] o uso da linguagem algébrica, para expressar generalizações que se constituam em propriedades de outros campos da Matemática, é outra função da álgebra que deve ser, pouco a pouco, introduzida (BRASIL, 2011, p. 18).

Desse modo, no ensino da Álgebra, em se tratando de materiais didáticos, os livros precisam trabalhar com situações que possibilitem que os alunos observem regularidades e generalizem modelos. O professor, com o auxílio do livro didático tem o papel de propor essas situações para os alunos, introduzindo assim o estudo da álgebra gradativamente.

Além do previsto no Guia do livro didático, no Referencial Curricular da Rede Estadual de Ensino Fundamental do Estado de Mato Grosso do Sul, em especial para o $8^{\circ}$ ano do Ensino Fundamental, os conteúdos de álgebra aparecem listados no item "Número e Operações" nesse Referencial, abordados em todos os bimestres do $8^{\circ}$ ano, como também previsto nos PCN (BRASIL, 1998).

Além da distribuição de conteúdos, nos PCN de Matemática (BRASIL, 1998) sugere-se explorar as dimensões da Álgebra como sendo: aritmética generalizada, funcional, equações e 
estrutural. No Quadro 1 apresentamos o resumo das diferentes dimensões da álgebra segundo os PCN (BRASIL, 1998, p. 116).

QUADRO 1 - Dimensões da álgebra.

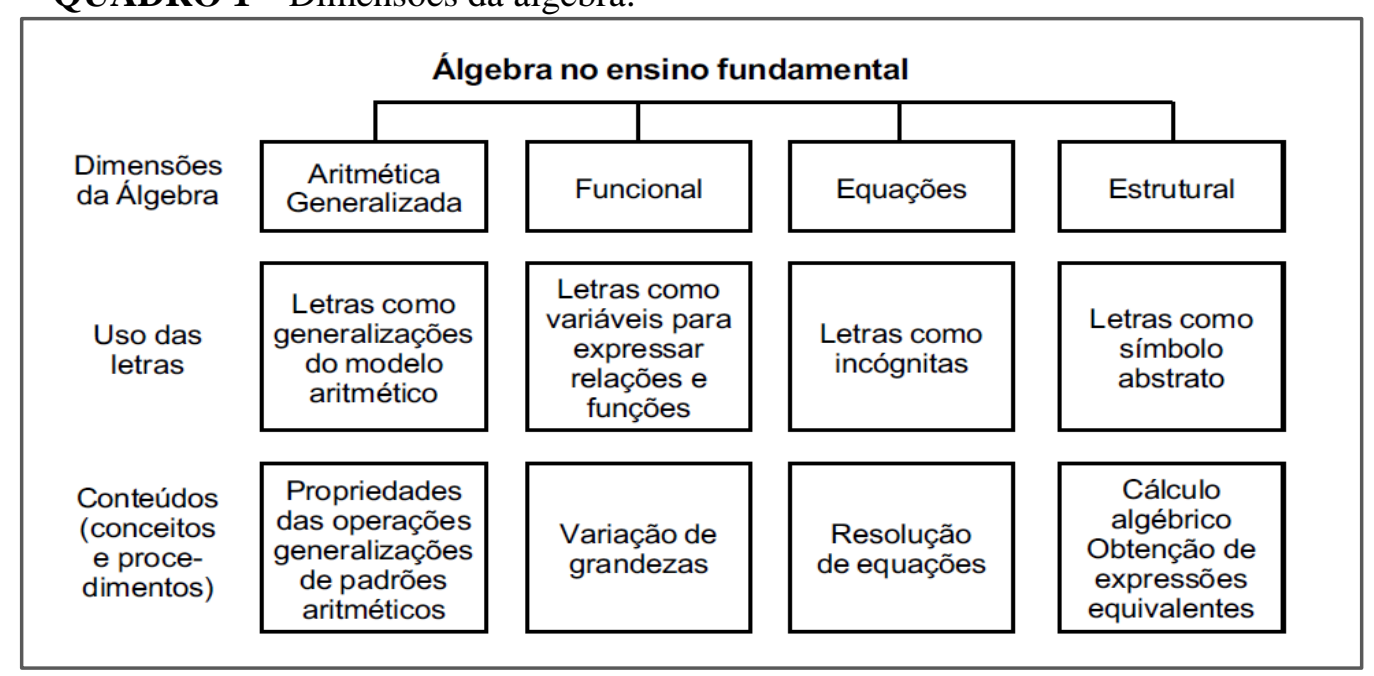

Fonte: (BRASIL, 1998).

Essas dimensões da álgebra precisam ser exploradas pelos professores para que o aluno possa desenvolver a compreensão dos conceitos algébricos que são engendrados por contextos diversos. Para tanto, é papel do professor propor situações didáticas que permitam a experiência dessas diferentes concepções para a construção do pensamento algébrico.

O significado de conceitos algébricos pode ser explorado também na perspectiva da linguagem digital. Desse modo, um dos caminhos é o uso das tecnologias digitais, em especial dos laptops que estão presentes nas escolas.

Com os laptops os professores podem trabalhar com alguns softwares e aplicativos específicos como os applets. Applet é um pequeno programa feito para ser usado em uma página da Internet. Com um applet pode-se realizar animações interativas, cálculos rápidos ou outras tarefas simples sem ter que mandar a requisição do usuário para o servidor de internet ou ocupar memória do computador. Ao usar os applets não há a necessidade de fazer download de softwares ou aplicativos, o que favorece o uso desses com os laptops, que possuem pouca memória. Por esse motivo, fez-se a opção na pesquisa pelo uso de applets com os professores que participaram desta pesquisa.

Para que a integração do laptop educacional aconteça de forma a provocar mudanças na escola, torna-se necessário que o professor atue em uma abordagem construcionista. De acordo com Almeida (2005), é necessário que o professor conheça as características, potencialidades e limitações das tecnologias digitais, de modo a desafiar, questionar e instigar o aluno a construir conhecimento, favorecendo a sua aprendizagem. Assim, o professor precisa planejar atividades conforme os objetivos de aprendizagem das aulas. 


\section{Uso dos laptops no ensino da álgebra: práticas pedagógicas de dois professores}

A seguir analisaremos aulas desenvolvidas pelos professores com o uso do laptop educacional no processo de ensino de e de aprendizagem.

Inicialmente analisaremos uma aula desenvolvida com o uso do laptop pela professora Joana no dia 22 de maio de 2013. Essa aula foi planejada também no dia 22 de maio de 2013, em um período anterior ao da aula. Ficou decidido no planejamento com a professora utilizar um applet de polinômios ${ }^{5}$, com o objetivo de "Identificar e reconhecer um polinômio e seu grau, e adicionar polinômios". Na metodologia da aula os alunos teriam que resolver as atividades propostas no applet, com orientação da professora. As atividades eram relacionadas a classificação de polinômios, adição de polinômios e identificação do grau de um polinômio. E a professora teria o papel de auxiliar os alunos nesse processo de resolução das atividades.

Joana iniciou a aula orientando:

Professora Joana: Pessoal entra, acessa a internet tá. Nós vamos ver polinômios que é o que a gente já tá vendo em sala, já fizemos até alguns exercícios [sobre isso] [...]

Professora Joana: A professora Fernanda vai por pra mim no quadro o endereço que vocês vão acessar na internet tá?

Aluno: É pra copiar professora?

Professora Joana: Sim. [...] (Aula do dia 22/05/2013 - grifo nosso)

A professora já havia iniciado o trabalho sobre polinômios com os alunos em aula anterior.

O início da aula que analisamos era para usar o laptop para analisar se os alunos identificavam monômios, binômios, e trinômios. A seguir apresentamos um diálogo realizado entre um aluno e a professora:

Aluno: É aquele site que é pra entrar?

Professora Joana: É pra entrar naquele lá, todos tem que entrar naquele site, vem cá se não eu nem vou poder te acompanhar.

Aluno: Abriu aqui professora.

Professora Joana: Tá, reconhecer as expressões algébricas, você vai ó monômio, binômio, trinômio você sabe quais são né?

Aluno: Monômio é quando é uma expressão, binômio é quando é duas expressões, trinômio é quando é três expressões.

Professora Joana: Colocou todo aquele endereço lá na barra encima?

Aluno: Sim.

Professora Joana: Tá [...] (Aula do dia 22/05/2013 - grifo nosso)

O aluno neste diálogo identifica cada termo da expressão algébrica como sendo uma expressão, e a professora não observou a possível confusão do aluno em relação aos termos e

\footnotetext{
${ }^{5}$ Disponível em: <http://quiz.uprm.edu/tutorial_es/ea/ea_home.html>.
} 
denominações. Em diálogo com outro aluno, observa-se pelos grifos destacados no diálogo a seguir, que a professora induz o aluno à resposta:

Professora Joana: Não encontrou o endereço? Então você digitou errado, volta a digitar [...] Se não tiver igualzinho lá vocês não vão conseguir acessar [...]

Professora Joana: Coloque ai para praticar se é binômio, trinômio...

Aluno: Professora eu não lembro.

Professora Joana: Lembra sim, você não viu os dois exemplos ali, tá vai abrir o exercício, ah fechou... isso ai a expressão essa é um binômio, um monômio ou trinômio? Qual que você acha que é?

Aluno: Peraí, eu acho...

Professora Joana: Binômio, monômio ou trinômio? Bi é o quê?

Aluno: Bi é dois.

Professora Joana: Tri é o quê?

Aluno: Três.

Professora Joana: E o mono?

Aluno: Um.

Professora Joana: Então esse ai é o que? Então clica em cima da palavra, não, não é trinômio isso agora enviar, ele vai falar se tá certo ou errado, olha lá ver solução detalhada certo? Ó correta, então sua solução tá correta, então agora volta novo pressione aqui para gerar outra pergunta, isso você vai aqui ó pra aparecer o exercício tá vai aparecer o exercício igual o dela ela já fez um [...]

Professora Joana: Ó isso aqui é trinômio, binômio ou monômio?

Aluno: Binômio.

Professora Joana: Bi, então clica na palavra isso e vem em enviar, ai ele vai falar pra você olha lá sua resposta esta correta. (Aula do dia 22/05/2013 - grifo nosso)

O aluno consegue realizar a atividade. Mas, são atividades caracterizadas como de abordagem instrucionista. E, essa atividade poderia ter sido realizada, da forma como foi realizada, sem levantamento de conjecturas, usando lápis e papel, quadro e giz. No entanto, podemos considerar que o applet tem o diferencial de fornecer ofeedback.

Mostramos na Figura 1 a atividade desenvolvida no diálogo anterior entre a professora e o aluno.

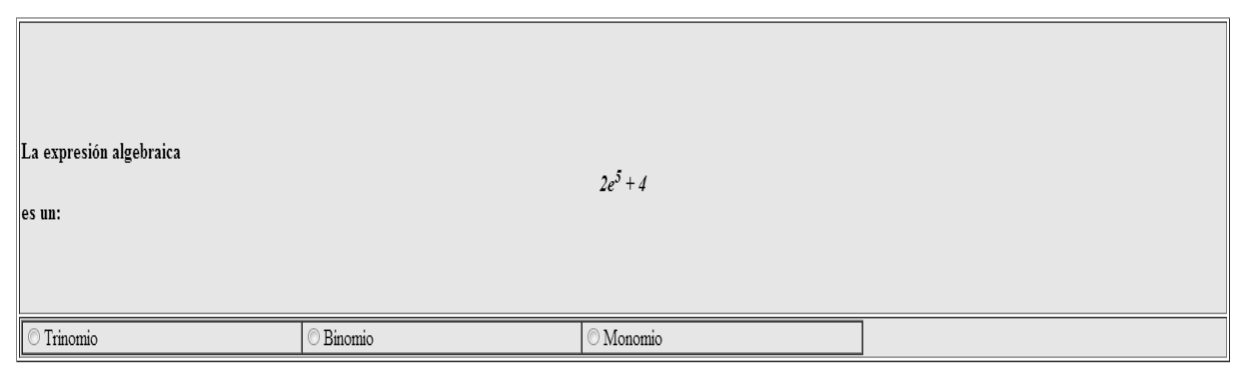

FIGURA 1: Atividade sobre expressões algébricas desenvolvida no applet Fonte: Dados da pesquisa 
Ao optar por uma das respostas, o applet fornecia o feedback conforme Figura 2, que pouco contribuía para a aprendizagem do aluno.

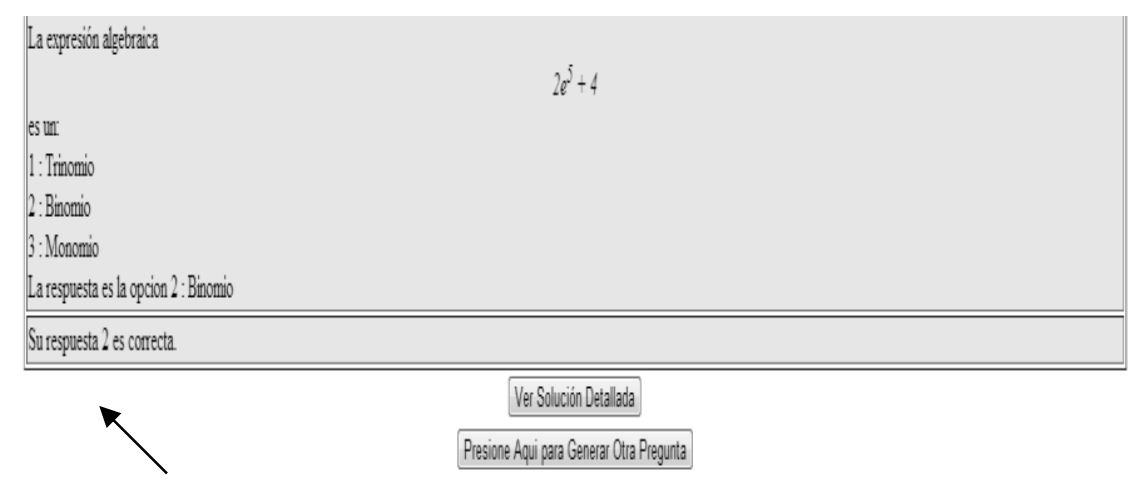

FIGURA 2: Resolução da atividade Fonte: Dados da pesquisa

Na sequência, foram desenvolvidas atividades de adição de polinômios. A seguir na Figura 3 mostramos a atividade proposta no applet.

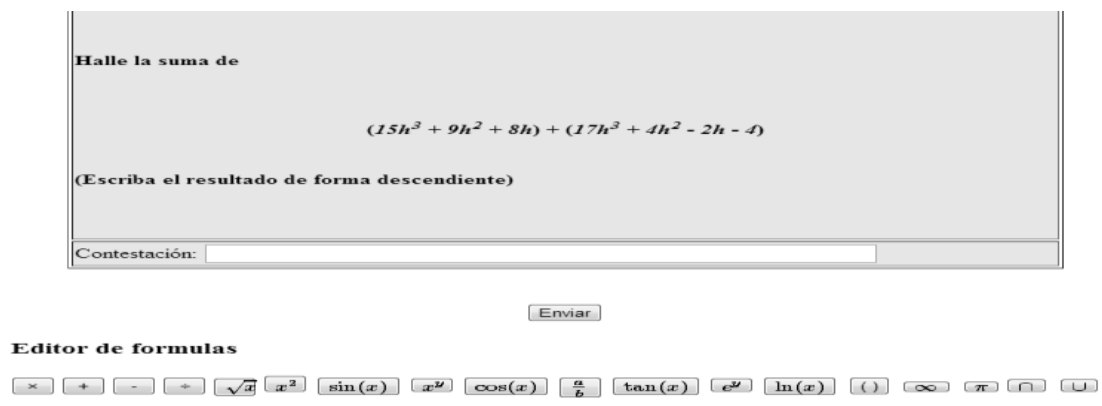

FIGURA 3: Atividade sobre adição de polinômios.

Fonte: Dados da Pesquisa.

Nessa atividade os alunos apresentaram bastante dificuldade em realizar as operações de adição dos termos dos polinômios. A professora Joana orientava os alunos, instruindo passo a passo o que tinham que fazer para resolver a atividade proposta. Como, por exemplo, Joana falava aos alunos: "você soma os termos correspondentes dos polinômios", "olha você pode somar os termos $9 h^{2}$ com $4 h^{2}$ dos polinômios, por serem correspondentes ok".

Observou-se que para resolver a atividade proposta de acordo com a Figura 3, o aluno precisava realizar a adição de dois polinômios, utilizando os símbolos disponíveis quando necessários. Apresentamos a seguir o feedback que o applet fornece para a operação. 


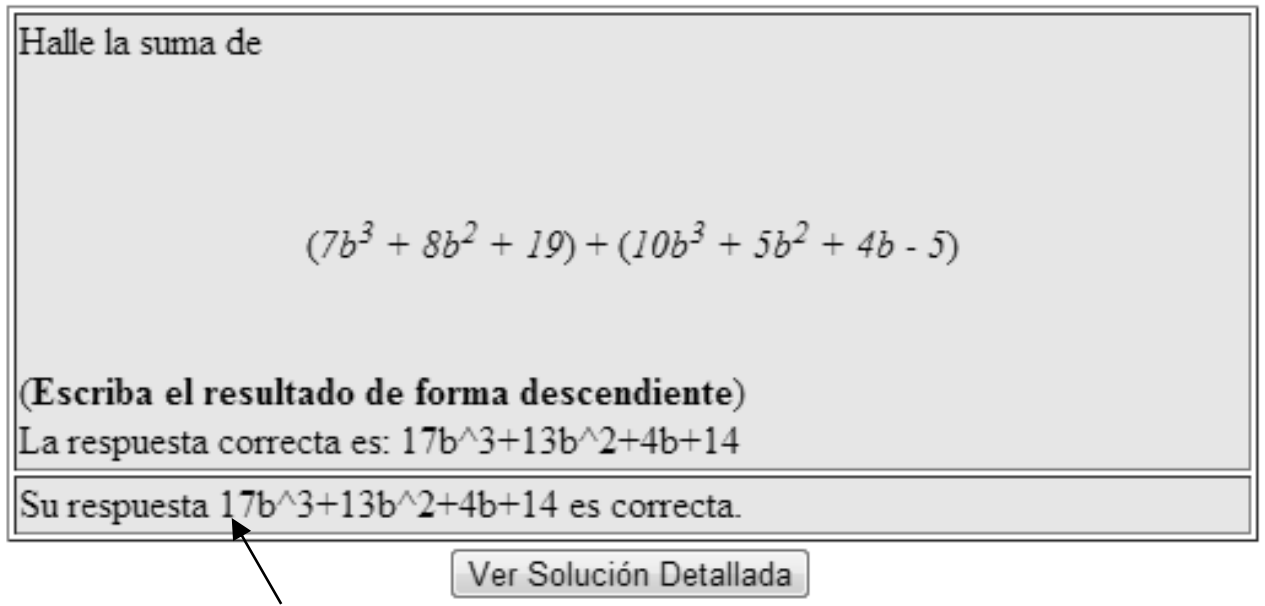

FIGURA 4: Resolução da atividade

Fonte: Dados da Pesquisa

$\mathrm{Na}$ aula, observou-se que quando um aluno solicitava a ajuda da professora, a mesma fornecia as respostas da atividade. No entanto, essa atividade poderia ser trabalhada sem o uso do laptop, com a diferença de que o aluno não teria o feedback que o applet fornece ao desenvolver cada atividade. Outra possibilidade para o professor trabalhar com esse applet no ensino de polinômios, além da trabalhada pela professora, seria explorar mais as conjecturas dos alunos, discutindo com eles o procedimento da soma de polinômios a partir das conjecturas levantadas.

Nesse processo, alguns alunos conseguiram compreender a operação de adição de polinômios, por exemplo, como mencionado no diálogo a seguir.

Professora Joana: Como você fez?

Aluno: Então, professora eu somei os que tinha c com dois e os que tinha c com 3 e os que só tinha c e número com número.

Professora Joana: Humm. Isso mesmo. Tá vendo, você precisa somar os termos que são comuns. (Aula do dia 22/05/2013 - grifo nosso)

Pelo diálogo, apesar de o aluno ter compreendido como adicionar dois polinômios, o mesmo utiliza em sua fala uma linguagem que não é adequada. No entanto, a professora observou e compreendeu que o aluno conseguiu desenvolver a atividade.

O conteúdo de polinômios previsto no $2^{\circ}$ bimestre no Referencial Curricular da Rede Estadual de Ensino - Ensino Fundamental do estado do Mato Grosso do Sul foi desenvolvido pela professora com o uso do laptop, com o auxílio do applet de polinômios como já apresentado. Nesse sentido, identificamos estas aulas como uma possibilidade de integração do laptop ao currículo escolar e à prática da professora.

A professora trabalhou em uma abordagem instrucionista (PAPERT, 2008), assim, um avanço nesta integração seria usar o applet em uma abordagem construcionista, explorando as conjecturas dos alunos, mesmo ao explorar o grau dos polinômios. Ou seja, ao iniciar o ensino 
destes conteúdos, usar o applet para levantamento de conjecturas, encontrar regularidades nos procedimentos necessários a identificação do grau do polinômio, soma de polinômios.

Muitas das atividades trabalhadas na aula observada foram semelhantes a essa, e os alunos, em sua maioria, conseguiram resolvê-las de modo correto.

A professora finalizou a aula solicitando aos alunos que encerrassem as atividades que estavam desenvolvendo e desligassem os laptops para que fossem levados a sala de tecnologia. Joana não realizou um fechamento dos estudos realizados na aula, discutindo e fazendo uma síntese dos conteúdos explorados com os alunos. No entanto, na aula seguinte sem o uso do laptop, a professora retomou o que tinha sido trabalhado na aula anterior com o applet, discutindo com os alunos sobre a classificação de polinômios e soma de polinômios.

Apesar de a pesquisadora ter participado do planejamento dessa aula, nada propôs para que a professora refletisse sobre a possibilidade de explorar o applet no levantamento de conjecturas. Assim o formador precisa ter formação também para que possa contribuir com a formação dos formadores. Ao analisarmos essa aula e seu planejamento, observamos o papel importante do formador no processo de formação e ação do professor em formação; ele precisa ter o conhecimento matemático, conhecimento de diferentes applets e softwares, e conhecimento de contribuições desses para a aprendizagem de conteúdos de matemática. Esses conhecimentos devem se articular com a sua atitude de orientador, questionador, que desafia os professores para a escolha de softwares ou applet, para uso em sala de aula, de maneira a contribuir com a aprendizagem do aluno em diferentes conteúdos.

Quanto à álgebra explorada nessas duas últimas aulas, de acordo com Usiskin (1995) no estudo de polinômios a concepção da letra utilizada é a de símbolo abstrato, e situa-se na concepção de estudo de estruturas. As letras nessa concepção são tratadas como sinais no papel, sem qualquer referência numérica.

A seguir apresenta-se uma aula desenvolvida pelo professor Carlos no dia 06 de março de 2013. Durante o planejamento foi decidido fazer uma sequência de atividades, em que se explorasse a fatoração numérica, e como o professor trabalharia com o applet de fatoração ${ }^{6}$, seria discutido a relação entre o cálculo da medida de área do retângulo e a forma fatorada de um número. Assim, o objetivo da aula foi definido: "Compreender a relação entre a medida de área do retângulo e a forma fatorada de um número".

Para analisar a abordagem com que o professor pretendia desenvolver a aula, a pesquisadora questionou o professor: “Como você avalia os alunos na aula?”, ou seja, como ele faria para saber se o objetivo da aula foi atingido. Carlos afirmou que:

\footnotetext{
${ }^{6}$ Apresentado anteriormente na metodologia e no trabalho pela professora Joana. Disponível em: <http://nlvm.usu.edu/en/nav/frames_asid_189_g_3_t_2.html?open=activities\&from=category_g_3_t_2.html>.
} 
Eu na verdade quando eu vou corrigir determinado conteúdo com eles, a gente tem mais ou menos uma ideia né? Eu chamo a participação de todos [os alunos] sabe, eu faço pergunta mesmo diretamente, [como, por exemplo,] fulano de tal como que fica isso aqui? E aí a outra eu verifico caderno por caderno. (Professor Carlos - planejamento do dia 13/03/2013 - grifo nosso)

Pela fala do professor, este questionava os alunos e a partir dos argumentos deles observava se estavam aprendendo determinado conteúdo, além de observar os registros nos cadernos. Assim, discutimos com Carlos como seria realizada a avaliação da aula com o uso do laptop. E ficou decidido que os alunos seriam avaliados a todo o momento, observando a representação geométrica no applet das expressões numéricas solicitadas. Nas discussões o professor mencionou que:

[...] a real mesmo dessas atividades [com o laptop], também é novidade pra mim sabe, embora eu gosto muito disso. [...] Hoje [quarta-feira] e amanhã [quinta-feira] né são quatro aulas, então a gente poderia fazer o seguinte. Acho que não dá pra fazer as duas atividades hoje, mas àquela da fatoração de representação geométrica acho que dá pra gente trabalhar aquela hoje. [...] e amanhã fazer alguma atividade relacionada a esse trabalho realizado no applet. (Professor Carlos - planejamento do dia 13/03/2013 - grifo nosso)

O professor ressaltou que não seria possível o trabalho em duas aulas com fatoração numérica e de expressões algébricas, mas que se deveria realizar o estudo de fatoração numérica.

As aulas desenvolvidas pelo professor referente à fatoração de expressões numéricas com o uso do laptop foram realizadas no dia 06 de março de 2013, no mesmo dia em que elaboramos o planejamento da aula. Assim, o professor Carlos iniciou a aula questionando os alunos: “Como que faz pra fatorar um número?".

Estavam presentes na sala, na aula do dia 06 de março de 2013, 12 alunos. Após distribuir os laptops, o professor passou no quadro o endereço do site em que estava o applet de fatoração, para os alunos acessarem. Alguns laptops estavam com a bateria descarregada, tendo que ser trocados, e alguns alunos demoraram a acessar o site, por terem dificuldades na compreensão da letra do professor no quadro. Em seguida, o professor orientou os alunos:

Ó pessoal é o seguinte, ó eu vou passar alguns números aqui pra vocês, e eu quero que vocês representem esses números aí [no laptop] na forma geométrica tá. $\mathrm{E}$ a forma fatorada vocês vão representar aí pra mim, na forma fatorada só que geometricamente aí tranquilo? [...] vocês vão utilizar isso aí [o applet de fatoração] tá, e vão representar esses números. Então, vou colocar os números aqui [no quadro] beleza. (Professor Carlos - aula do dia 06/03/2013)

Foram observadas algumas dificuldades na fala do professor para explicar aos alunos a proposta da atividade. No grifo na fala do professor, ele parece indicar que os alunos inicialmente fatorem os números, e que representem a forma fatorada dos mesmos geometricamente, a partir da representação de um retângulo. Mas, a proposta era que os alunos, a partir do número dado, que o considerassem a medida de área de uma região retangular, cuja unidade de medida fosse dada pela superfície de um quadradinho no applet. E, ao obter a representação do retângulo, observassem que 
a medida da área delimitada por ele poderia ser obtida pelo produto das medidas dos seus lados. Ou seja, o número dado poderia ser escrito na forma de um produto de dois números.

A sequência de números sugerida foi: 10, 18, 8, 27, 32, 14, 21. O professor apresentou uma solução para a fatoração do número 10: "Pessoal vamos pensar assim ó, eu posso pegar o número 10 aqui ó. Como que eu o represento na forma fatorada? Vou fatorar ó dá por quantos?” E assim foi mostrando para os alunos como fatorar o número, dando os passos, de forma numérica, sem usar o applet. A seguir apresentamos um diálogo do professor com uma aluna durante a aula, em que se observou que a aluna conseguiu representar o número 10 como medida de área de uma região retangular, usando o applet.

Aluna: Professor vem cá fazendo favor.

Professor Carlos: Estou indo aí. Como que eu posso representar o número 10 aí no laptop?

Aluna: Fazendo 2x5, daí eu vou pegar dois desse e colocar.

Professor Carlos: Isso! Isso! Isso! Isso! Joga esses outros na lixeira. Desce ele todo, traz ele pra cá agora aí. Isso, beleza, muito bem.

Professor Carlos: Fala pra elas [outras alunas] agora como que faz. Não! Deixa, elas pensarem! (Aula do dia 06/03/2013 - grifo nosso)

Nesse diálogo observa-se que o professor fornece as respostas para a aluna, não possibilitando que ela tenha papel ativo na resolução da atividade, apresentando características da abordagem instrucionista (PAPERT, 2008). Destacamos ainda que ele não parte da ideia de que o número 10 deve representar a medida de área da região retangular, ele parte das medidas dos lados da figura, ou seja, da representação geométrica do número 10 em uma forma fatorada. Nesse sentido, é importante refletir sobre a contribuição dessa atividade para a aprendizagem do aluno.

Ainda no diálogo, destacamos o momento em que o professor reflete sobre sua ação, logo após sugerir para a aluna "mostrar" para as colegas, como fazer. Essa reflexão aparece quando ele, logo em seguida, solicita que a aluna deixe que as colegas pensem na atividade. Destaca-se a seguir um diálogo do professor com outra aluna:

Aluna B: Não entendi nada professor.

Professor Carlos: Isso aqui não foi você que colocou?

Aluna B: Não. Estava aí.

Professor Carlos: Não, que eu achei legal. Tá eu quero que você me fale o seguinte, o número 10, eu tô representando aqui em fatores primos, eu quero que você representa aí [no applet] pra mim na forma geométrica. Como que eu posso representar ele aí [no applet]? Como que eu faço pra representar $2 \times 5$ aí?

Aluna B: Humm... (Aula do dia 06/03/2013 - grifo nosso)

Nesse diálogo o professor fez alguns questionamentos para a aluna a fim de que ela pensasse na atividade. No entanto, pelo diálogo anterior o professor Carlos forneceu algumas 
respostas, e sugeriu que o aluno representasse o produto de 2 por 5 , não o número 10 , como discutido anteriormente. Nesse sentido, o professor assumiu uma abordagem com características do instrucionismo (PAPERT, 2008), e não explorou o applet para que as alunas compreendessem a fatoração a partir da representação da medida de área de regiões retangulares. Na Figura 5 apresentamos a representação de um aluno para o número 18.

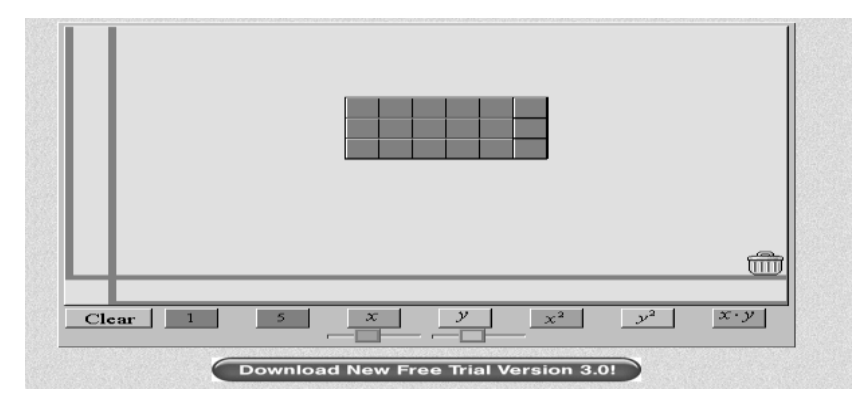

FIGURA 5 - Representação do número 18 pelo aluno M Fonte: Dados da pesquisa.

Observa-se que esse aluno conseguiu representar o número 18 a partir da representação de um retângulo de medidas de lado 3 e 6 unidades. Durante o desenvolvimento da aula, o professor Carlos manteve uma postura de questionar os alunos sobre as atividades, possibilitando a reflexão deles durante as mesmas, mas em alguns momentos forneceu algumas respostas em suas perguntas. A Figura 6 mostra uma representação do número 18 por outra aluna da turma.

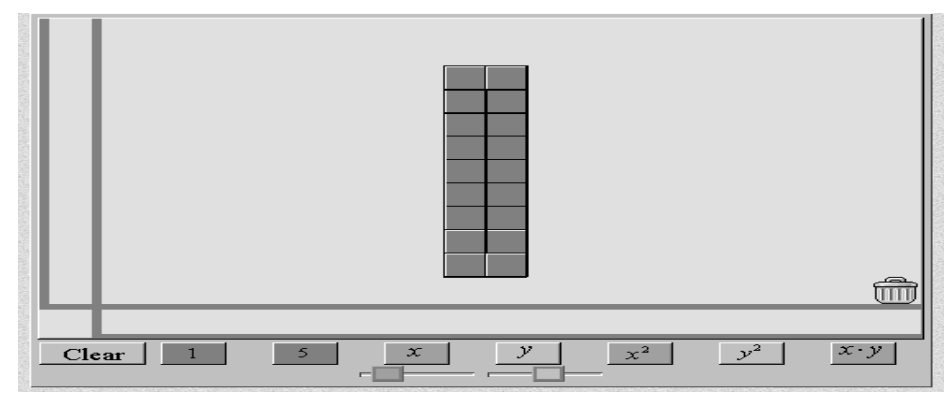

FIGURA 6: Representação do número 18 pela aluna N.

Fonte: Dados da pesquisa

A aluna representou o número 18 usando como medida dos lados do retângulo, 2 e 9 unidades. No momento em que o professor discutiu a fatoração do número 18 , ele fez a observação das diferentes representações geométricas feitas pelos alunos, disse que ambas estavam corretas. $\mathrm{O}$ professor realizou um fechamento dos estudos realizados em aula discutindo com os alunos as representações geométricas realizadas. Ele também questionou os alunos sobre como tinham realizado as representações geométricas dos números solicitados, e discutiu diferentes estratégias dos alunos e as contribuições do applet para a aprendizagem deles, como a visualização e a manipulação. Pelos registros da observação da aula, o professor contou com o envolvimento dos alunos na atividade. 
Consideramos que essas aulas também são uma possibilidade de integração do laptop ao currículo de matemática e à prática pedagógica do professor, pois o uso está articulado com o conteúdo do currículo prescrito, com foco na aprendizagem dos alunos.

\section{Algumas Considerações}

Consideramos que a professora Joana apresentou características da abordagem instrucionista no uso dos laptops em sua prática pedagógica, pois fornecia respostas das atividades para os alunos, algumas vezes o "passo a passo" para resolver a atividade. A professora realizou algumas ações de integração do laptop ao ensino de álgebra do $8^{\circ}$ ano, pois esta turma apresentava mais conteúdos da álgebra em sua proposta curricular. Nas aulas em que foi abordado o estudo de polinômios, observamos ações de integração do laptop, mas ainda é possível avançar, especialmente se considerarmos a importância de ações em uma abordagem construcionista.

O professor Carlos apresentou características da abordagem instrucionista no uso dos laptops em sua prática pedagógica, fornecendo respostas aos alunos, ao tentar questioná-los. Mas, observamos alguns momentos em que o professor buscou atuar em uma abordagem construcionista, como ao questionar os alunos e deixá-los resolver os problemas. Ele também procurou articular as aulas, e no processo de integração, desenvolveu aulas explorando o conteúdo de fatoração numérica, com o objetivo de contribuir com o processo de aprendizagem dos alunos.

De forma geral, durante o desenvolvimento da pesquisa, observamos que os professores apresentaram algumas possibilidades de integração do laptop ao ensino de álgebra do $8^{\circ}$ ano, observada a proposta curricular do estado e do país. No entanto, eles não o integraram a sua prática pedagógica, pois isso é um processo e esses professores precisam continuar participando de formações continuadas para conhecerem mais possibilidades de trabalho com computadores portáteis, desenvolvendo autonomia em relação a esse processo.

O modelo de formação continuada em serviço que compôs o plano de fundo desta pesquisa é um caminho para continuarmos pesquisando a integração das tecnologias digitais às práticas pedagógicas. Neste modelo, os professores são acompanhados por pesquisadores em suas ações cotidianas no espaço da escola, elaborando o planejamento de aulas em conjunto, sendo observados em suas aulas e realizando avaliações de suas práticas pedagógicas ao longo do processo, podendo reconstruí-las.

\section{Referências}

ALMEIDA, Maria Elizabeth Bianconcini. Informática e Formação de professores. Brasília. Ministério da Educação, 2000. (Coleção Informática para mudança na Educação). 
. Tecnologia, currículo e projetos - Prática e formação de professores na integração de mídias. In: MORAN, José Manuel. (Org.). Integração das Tecnologias na Educação. Brasília, DF: Secretaria de Educação a Distância - Ministério de Educação MEC, 2005. p. 38-45.

BITTAR, Marilena. A Escolha do Software Educacional e a Proposta Didática do Professor: estudo de alguns exemplos em matemática. In: BELINE, Willian; COSTA, Nielce Meneguelo Lobo da. (Orgs.). Educação Matemática, Tecnologia e Formação de Professores: algumas reflexões. Campo Mourão -PR: Editora de Fecilcam, 2010. p. 215-243.

BRASIL. Parâmetros Curriculares Nacionais: Matemática. Secretaria da Educação Fundamental. Brasília: MEC/SEF, 1998.

Programa um computador por aluno (PROUCA). Disponível em: <http://www.uca.gov.br/institucional/downloads/workshop3_VisaoGeral.pdf>. Acesso em: 25 mai. 2012.

GIL, Katia Henn. Reflexões sobre as dificuldades dos alunos na aprendizagem de álgebra. 2008. 118 f. Dissertação (Mestrado em Educação em Ciências e Matemática) - Pontifícia Universidade Católica do Rio Grande do Sul, Porto Alegre, 2008.

\section{MATO GROSSO DO SUL. Referencial Curricular da Rede Estadual de Ensino - Ensino Fundamental. Secretaria de Educação, 2012. Disponível em: <http://intra.sed.ms.gov.br/portal/Arquivos/Publicos/referencial_curricular_completo_ensino_funda mental_VERSAO_PRELIMINAR.pdf>. Acesso em: 05 de nov. 2013. (versão preliminar).}

PAPERT, Seymour. A máquina das crianças: repensando a escola na era da informática; tradução Sandra Costa. - ed. rev. -- Porto Alegre: Artmed, 2008.

VALENTE, José Armando. Espiral da espiral de aprendizagem: o processo de compreensão do papel das tecnologias de informação e comunicação na educação. 2005. Tese (Livre-Docência), Universidade estadual de Campinas, São Paulo, 2005.

VIOLA DOS SANTOS, João Ricardo. O que alunos da Escola Básica mostram saber por meio de sua produção escrita em matemática. 2007. Dissertação de Mestrado, Universidade Estadual de Londrina, UEL, 2007.

ZABALA, Antoni. A prática educativa: como ensinar. Porto Alegre: ArtMed, 1998.

Recebido em: 30.07.2014 Aceito em: 04.11.2015 